\section{Evaluation of psychological performance strategies of volleyball players}

\section{Voleybolcuların psikolojik performans stratejilerinin belirlenmesi $^{1}$}

\author{
Aylin Özgen Feralan ${ }^{2}$ \\ Serkan İbiş ${ }^{3}$ \\ Bülent Okan Miçooğulları ${ }^{4}$
}

\begin{abstract}
Aim: The aim of this study was to examine the performance strategies of volleyball players and also comparison of usage levels of strategies in training and competitions.

Method: Total 134 voluntary amateur volleyball players between the ages of 15-24 participated in the study. Performance strategies of volleyball players were determined with Test of Performance Strategies that designed by Thomas et al., (1999). To examine the performance strategies of volleyball players and also comparison of usage levels of strategies in training and competitions Statistical Package for Social Sciences (SPSS) programme was employed. To define possible differences between variables Independent samples $t$ test was used.
\end{abstract}

Findings: Practice scale's highly used strategy was self-talk and the lowest usage percentage was attention control. Meanwhile, competition scale results indicated that the highest used strategy was activation and lowest used strategy was relaxation. While comparison of differences

\section{Özet}

Amaç: $\mathrm{Bu}$ çalışmanın amacı, voleybolcuların kullandıkları psikolojik performans stratejilerinin incelenmesi ve antrenmanlarda ve müsabakalarda kullanılan stratejilerin kullanım düzeylerinin karşılaştırılmasıdır.

Metod: Çalışmaya 15-24 yaş arasında 134 gönüllü voleybolcu katılmıştır. Sporcuların kullandıkları psikolojik performans stratejilerini ve bu stratejilerin düzeylerini belirlemek üzere Thomas ve ark. (1999) tasarladığ1 Psikolojik Performans Stratejileri testi kullanılmıştır. İstatistiki analizlerin yapilması amaciyla Sosyal Bilimler için İstatistik programı kullanılmıştır. Olası farklılıkların tespiti için Bağımsız Örneklem t testi kullanılmıştır.

Bulgular: Antrenman alt ölçeğinde kullanılan stratejiler arasında en yüksek ortalama kendinle konuşma becerisi; en az kullanilan ise dikkat kontrolü saptanmıştrr. Müsabaka alt ölçeğinde ise en fazla kullanilan strateji olarak da aktivasyon becerisi; en düşük düzeyde kullanılan beceri stratejisi de rahatlama olarak bulunmuştur. Kullanılan becerilerin

\footnotetext{
${ }^{1}$ Bu çalışma Aylin Özgen Feralan'ın Yüksek lisans tezinden elde edilmiştir.

${ }^{2}$ Antrenör, Nevşehir Gençlik ve Spor İl Müdürlüğü, aylinzgn@gmail.com (D) Orcid ID: 0000-0001-7860-1533

3Prof. Dr., Niğde Ömer Halisdemir Üniversitesi, Spor Bilimleri Fakültesi, serkanibis@,ohu.edu.tr (iD) Orcid ID: 0000-0002-5154-3086

${ }^{4}$ Doç. Dr., Nevşehir Hacı Bektaş Veli Üniversitesi, Eğitim Fakültesi, Beden Ĕğitimi Öğretmenliği Bölümü, omicoogullari@nevsehir.edu.tr (iD) Orcid ID: 0000-0001-5258-5766
} 
Feralan, A. Ö., İbiş, S., \& Miçooğulları, B. O. (2020). Voleybolcuların psikolojik performans stratejilerinin belirlenmesi. Journal of Human Sciences, 17(3), 812-821. doi:10.14687/jhs.v17i3.5963

between practice and competition scales karşlaşturılması sonucunda hedef belirleme ve strategies, it was found that except of goal imgeleme becerileri dişindaki tüm becerilerde setting and imagery all other strategies showed anlamlı farkllik bulunmuştur.

significant differences.

Conclusions: Psychological performance Sonuç: Voleybolcuların psikolojik becerileri strategies' averages of volleyball players were ensured and it is exhibited that to which strategies should be thought and focused.

kullanım düzeyleri ve ne tür becerilerin daha fazla oranda çalıştırılması gerektiği ortaya koyulmuştur.

Anahtar Kelimeler: Voleybol, psikolojik beceri, Keywords: Volleyball, psychological skills, psikolojik stratejiler. psychological strategies.

(Extended English summary is at the end of this document)

\section{Giriş}

Psikolojik performans stratejilerini doğru seçip verimli bir uygulama süreci gösterebilen sporcular baskı altındayken bile istenen performansı göstererek, önceden belirlenen oyun planlarını diğerlerine göre daha etkin kullanabilmekte ve karşılaşılan zorluklara daha yaratıcı çözüm yolları bulabilmektedir. Ayrıca efektif olarak konsantre olabilmekte, kapasitesinin sınırlarını zorlayabilmekte, branşı ile ilgili öğrenmesi gereken yeni teknikleri daha çabuk kavrayabilmektedir. Sporcunun psikolojik avantajları, spor psikolojisi bilimi içinde değerlendirilmektedir (Mckay, 2001).

Psikoloji bilimi davranışları ve zihinsel süreçleri açıklamaya çalışan bilim olarak tanımlanırken; Spor Psikolojisi, zihinsel süreçleri sportif bağlamda açılamaya çalışan bir bilim olarak nitelendirilmektedir (Brewer, 2009). Spor psikolojisi müsabık olan sporcu davranışlarının dışında rekreasyonel boyutta egzersiz, serbest zaman ve zindelik için yapılan fiziksel aktiviteleri de kapsar (Moran, 2004). Aynı zamanda spor psikolojisi bir disiplindir. Teorik altyapısı olduğu kadar, uygulamalı olarak incelenebilen bir altyapı da içermektedir (Moran, 2004). Spor psikolojisi, sporda başarılı performans ile ilgili olan birçok prensibin evrensel olarak uygulanabilir olmasıdır (Aşçı ve ark., 2011). Spor psikolojisi, sporcuların yaşamlarını zenginleştirirken; yapılan uygulamalar vasıtasıyla (bunların bir örneği de psikolojik beceri antrenmanıdır) sportif performanslarını arttırarak sporcuları güçlendirmektedir (Karageorghis ve Terry, 2009).

Psikolojik beceri antrenmanlarının sporcuların performansına ve günlük yaşamlarındaki birçok sosyal-psikolojik parametrelere olumlu katkıları belirlemiştir. Sporculara uygulanan psikolojik beceri antrenmanlarının etkili ve verimli olup olmadığının belirlenmesinin en geçerli yollarından biri sporcunun antrenman ve müsabakalarda karşılaştığı psikolojik süreçlere karşı kullandığı psikolojik performans stratejilerinin belirlenmesidir (Burton ve Raedeke, 2008).

Spor ortamlarında karşılaşılan problematik durumlara tepkilerimiz ağırlıklı olarak yorumsal ve deneyimsel faktörlere bağlıdırlar ve bu tepkiler bireysel ve kendine özgüdür. Her sporcu gelişen olaylara yaklaşım tercihlerine göre farklılaşmaktadır. Bu bariz bakış açısı göstermektedir ki her sporcu için belirli zihinsel stratejileri başkaları için olduğuna göre daha uygundur. Farklı sporcular belirli stratejilerle daha iyisini yaparken diğerleri bunu gerçekleştiremeyebilir. $\mathrm{Bu}$ süreçleri sporcuların kullandıkları farklı psikolojik stratejiler olarak açıklanabilir (Thomas ve ark., 1999). Bilimsel boyutta sporcuların psikolojik performans stratejilerini belirleme çabaları Loehr'un 1986 yılında geliştirdiği Psikolojik Performans ölçeği ile başlamıştır. Sonrasında Mahoney ve ark. (1987), günümüze kadar birçok defa kullanılma başarısı gösteren Sporda Psikolojik Beceri ölçeğini geliştirmişlerdir. Psikolojik performans stratejilerinin ölçülebilmesi ve belirlenebilmesi için düzenlenen son ölçek Thomas ve ark., (1999) tarafindan "başarılı sporcu performanslarının" altında yatan psikolojik süreçleri ve parametreleri belirlemek amaciyla düzenlenen psikolojik performans stratejileri ölçeğidir. 
Feralan, A. Ö., İbiș, S., \& Miçooğulları, B. O. (2020). Voleybolcuların psikolojik performans stratejilerinin belirlenmesi. Journal of Human Sciences, 17(3), 812-821. doi:10.14687/jhs.v17i3.5963

Araştırmaya konu olan psikolojik beceriler ile ilgili bilimsel sonuçlar incelendiğinde psikolojik performans stratejileri başlığ altunda sporcuların kullandıkları stratejiler ve kullanım düzeyleri başarılı sportif performans için önemli olduğuna inanılmakta ve birçok antrenör, sporcuların bu stratejilerini göz ününde bulundurarak psikolojik performans planlamasını yaparken bu olgulara da dikkat etmeleri gerektiğini ifade etmektedirler (Thomas ve ark., 1999; Hanton ve ark., 2008; Holland ve ark., 2010; Clowes ve Knowles, 2013; Kalmar ve ark., 2014; Tanaka ve Gould, 2015; Miçooğulları, 2017).

Bu bilgiler ışığı altında, yapılan çalışmada ülkemiz spor psikolojisi alanyazının da kullanılma sıklığ1 henüz olması gereken seviyede olmayan psikolojik performans stratejileri ele alınmıştır. Buna göre, Nevşehir ili içerisinde lisanslı olacak şekilde voleybol sporcusunun, antrenman ve müsabaka ortamlarında kullandıkları psikolojik performans stratejilerinin belirlenmesi ve hangi düzeyde kullanıma oranlarına sahip olduklarının ortaya konulması amaçlanmıştır.

\section{Yöntem}

\subsection{Araştırma Modeli}

Araştırmada tarama modellerinden olan genel tarama modeli kullanılmıştır. Tarama modeli, "çok sayıda elemandan oluşan bir evrende, evren hakkında genel bir yargıya varmak amaciyla, evrenin tümü ya da ondan alınacak bir grup, örnek veya örneklem üzerinde yapilan tarama düzenlemeleridir” (Karasar, 2015).

\section{2. Örneklem}

Araştırmanın evrenini Nevşehir ilinde bulunan 350 adet lisanslı Voleybolcu içerisinden 1524 yaşları arası sporculardan kolayda örnekleme yöntemi yoluyla seçilmiş sporculardan oluşturmaktadır. Araştırmaya 15-24 yaşları arasında 134 sporcu gönüllü olarak katılmıştır. Çalışmaya katılan sporcular branşları itibariyle haftada en az 3 gün antrenman yapan sporculardan seçilmiştir. Sporculara çalısmanın amacı hakkında bilgi verilmiş, istek ve motivasyon düzeyleri yükseltilip maksimal düzeyde katulımları sağlanmıştır.

\subsection{Veri toplama arac1}

\subsubsection{Psikolojik Performans Stratejileri Testi (PPSTÖ)}

Ölçekteki maddeler likert tipi 5'li ölçek ("hiç uygulamıorum" seçeneğinden "daima uyguluyorum" seçeneğine) kullanılarak cevaplandırılmaktadır. "1" antrenmanda veya müsabakada karşlaştıkları özel durumlarda ilgili psikolojik stratejiyi hiç kullanmadıkları. " 5 " antrenmanda veya müsabakada karşılaştıkları özel durumlarda ilgili psikolojik stratejiyi daima uyguladıklarını ifade etmektedir. Bu bağlamda; katılımcılar "antrenman performansımı arttırmak için kendimle bazı konularda konuşurum", "Müsabaka esnasında kendi kendime spesifik sonuç hedefleri belirlerim" v.b. sorulara cevap vermişlerdir.

Orijinal ölçek antrenman ve müsabaka periyodu için çoğunluğu aynı olan sadece bir değişikliğin olduğu 8 adet alt boyuttan oluşmaktadır. Bunlar; Aktivasyon, Otomatizasyon, Duygusal Kontrol, Hedef Belirleme, İmgeleme, Negatif Düşünce (antrenman periyodu için Dikkat Kontrolü), Kendi kendine konuşma ve Gevşeme alt boyutlarıdır. Ölçek toplamda 64 sorudan oluşmaktadır.

Ölçeğin Türkiye popülasyonuna uyarlama çalışması Miçooğulları (2017) tarafindan, açıklayıcı ve tanımlayıcı faktör analizi teknikleri kullanılması vasıtasıyla geçerlik ve güvenirlik çalışması gerçekleştirilmiştir. Orijinal hali 64 madde şeklinde olan ancak yapılan analiz sonuçları doğrultusunda 60 maddeye düşen ölçek içerisinde, 30 madde ve 8 alt boyut müsabakaya (yarışmaya) dayalı diğer 30 madde ve 8 alt boyut ise antrenman ortamlarına dayalı gözlenen psikolojik performans stratejilerini içermektedir. Ölçek içerisinde otomatizasyon alt boyutu 2 madde geriye kalan tüm alt boyutlar 4'er madde içermektedir. Psikolojik Performans Stratejileri Ölçeği alt boyutları Güvenirlik Katsayıları-Cronbach's Alpha değerleri: antrenman alt boyutları için .83 olarak, müsabaka alt boyutları için toplamda .88 olarak belirlenmiştir. Bu değer tüm modelin güvenirliği için kabul edici düzeyde bir sonuç olarak saptanmıştır. 
Feralan, A. Ö., İbiș, S., \& Miçooğulları, B. O. (2020). Voleybolcuların psikolojik performans stratejilerinin belirlenmesi. Journal of Human Sciences, 17(3), 812-821. doi:10.14687/jhs.v17i3.5963

\subsection{Verilerin Analizi}

Verilerin analizinde SPSS 22.0 paket programı kullanılmıstır. Verilerin analizinde tanımlayıcı istatistik tekniklerinden Frekans - Yüzde, aritmetik ortalama ve standart sapma değerleri hesaplanmıştır. Verilerin normallik testi değerleri Shapiro-Wilk's ve Kolmogorov-Smirnov testleri ile belirlenmiştir. Yorumlayıcı istatistik tekniklerinde ise sonuçlar arasındaki ilişkiyi analiz etmek için "Bağımsız Örneklem t testi" kullanılmışır. Anlamlılık düzeyi $\mathrm{p}<.05$ olarak kabul edilmiştir. Araştırmada kullanılan istatistiki analizler ve bu analizler sonucu ulaşılan değerler aşağıda tablo halinde verilmiştir.

\section{Bulgular}

Bu bölümde araştırmanın amacında yer alan soruya cevap aramak üzere toplanan bilgilerin analizi sonucu elde edilen bulgulara yer verilmiştir. $\mathrm{Bu}$ araştırmanın temel problemini; "Voleybolcuların antrenmanlarda ve müsabakalarda kullandıkları psikolojik performans stratejilerinin belirlenmesi ve incelenmesi" oluşturmaktadır.

Tablo1. Arasstırmaya katılan sporcularn cinsiyetlerine göre dağıllımı

\begin{tabular}{ccccc}
\hline Cinsiyet & & Kadın & Erkek & Toplam \\
\hline & $\mathrm{N}$ & 90 & 44 & 134 \\
& $\%$ & 68.00 & 32.00 & \\
\hline
\end{tabular}

Araştırmada denek olarak 90 kadın, 44 erkek, toplam 134 öğrenci incelenmiştir. Araştırmanın veri toplama araçları ile elde edilen veriler çeşitli istatistiksel işlemlerden sonra tablolar halinde sunulmuştur. Tablo 1'e göre araştırmaya katılan, voleybol oynayan ve yarışmalara katılan lisanslı 90 (\% 68.00) kadın, 44 (\% 32.00) erkek sporcu olduğu görülmektedir.

Tablo 2: Psikolojik Performans Stratejileri ölçeği antrenman sürecinde kullanulan alt boyutlar tanımlayıc istatistikleri

\begin{tabular}{cccc}
\hline Alt Boyutlar & $\mathbf{N}$ & $\overline{\boldsymbol{x}}$ & Ss \\
\hline Kendinle Konuşma & 134 & 3.75 & .67 \\
Duygusal Kontrol & 134 & 3.32 & .63 \\
Otomatizasyon & 134 & 3.53 & .73 \\
Hedef Belirleme & 134 & 3.38 & .59 \\
İmgeleme & 134 & 3.22 & .65 \\
Aktivasyon & 134 & 3.26 & .57 \\
Dikkat Kontrolü & 134 & 3.22 & .66 \\
Rahatlama Becerisi & 134 & 3.48 & .66 \\
\hline
\end{tabular}

Psikolojik performans stratejileri ölçeğinin antrenman bölümü için var olan alt boyutlarının araştırma içerisinde kullanılan sporcuların tanımlayıcı istatistik değerlerinden, aritmetik ortalama ve standart sapma puanları incelendiğinde (Tablo2.), kendinle konuşma alt boyutunda sporcuların puanlarının ortalamaları $x=3.75 \pm .67$ olarak bulunmuştur. Duygusal kontrol alt boyutu puanlarının ortalaması $x=3.32 \pm .63$ olarak görülmüştür. Otomatizasyon alt boyutu puanlarının ortalaması $x=3.53 \pm .73$ olarak saptanmıştır. Hedef belirleme alt boyutu puanlarının ortalaması $x$ $=3.38 \pm .59$ olarak görülmüştür. İmgeleme alt boyutu puanlarının ortalaması $x=3.22 \pm .65$ olarak hesaplanmıştır. Aktivasyon alt boyutu puanlarının ortalaması $x=3.26 \pm .57$ olarak belirlenmiştir. Dikkat kontrolü alt boyutu puanlarının ortalaması $x=3.22 \pm .66$ olarak saptanmıştır. Sekizinci ve 
Feralan, A. Ö., İbiș, S., \& Miçooğulları, B. O. (2020). Voleybolcuların psikolojik performans stratejilerinin belirlenmesi. Journal of Human Sciences, 17(3), 812-821. doi:10.14687/jhs.v17i3.5963

son alt boyut olan rahatlama becerisi alt boyutu sonuçları incelendiğinde ise puanların ortalaması $x$ $=3.48 \pm .66$ şeklinde bulunmuştur.

Tablo 3. Psikolojik Performans Stratejileri ölçĕgi müsabaka sürecinde kullamlan alt boyutları tanmmlayıc istatistikleri

\begin{tabular}{cccc}
\hline Alt Boyutlar & $\mathbf{N}$ & $\overline{\boldsymbol{x}}$ & Ss \\
\hline Kendinle Konuşma & 134 & 3.38 & .68 \\
Duygusal Kontrol & 134 & 3.13 & .80 \\
Otomatizasyon & 134 & 3.12 & .87 \\
Hedef Belirleme & 134 & 3.46 & .65 \\
İmgeleme & 134 & 3.33 & .72 \\
Aktivasyon & 134 & 3.61 & .90 \\
Negatif Düşünce & 134 & 2.85 & .61 \\
Rahatlama Becerisi & 134 & 3.09 & .66 \\
\hline
\end{tabular}

Psikolojik performans stratejileri ölçeğinin müsabaka bölümü için var olan alt boyutlarının araştırma içerisinde kullanılan sporcuların tanımlayıcı istatistik değerlerinden, aritmetik ortalama ve standart sapma puanları incelendiğinde (Tablo3.), kendinle konuşma alt boyutunda sporcuların puanlarının ortalamaları $\overline{\boldsymbol{x}}=3.38 \pm .68$ olarak bulunmuştur. Duygusal kontrol alt boyutu puanlarının ortalaması $\overline{\boldsymbol{x}}=3.13 \pm .80$ olarak görülmüştür. Otomatizasyon alt boyutu puanlarının ortalaması $\overline{\boldsymbol{x}}=3.12 \pm .87$ olarak saptanmıştır. Hedef belirleme alt boyutu puanlarının ortalamas1 $\overline{\boldsymbol{x}}=$ $3.46 \pm .65$ olarak görülmüştür. İmgeleme alt boyutu puanlarının ortalaması $\overline{\boldsymbol{x}}=3.33 \pm .72$ olarak hesaplanmıştır. Aktivasyon alt boyutu puanlarının ortalaması $\overline{\boldsymbol{x}}=3.61 \pm .90$ olarak belirlenmiştir. Negatif Düşünce alt boyutu puanlarının ortalaması $\overline{\boldsymbol{x}}=2.85 \pm$.61 olarak saptanmıştır. Sekizinci ve son alt boyut olan rahatlama becerisi alt boyutu sonuçları incelendiğinde ise puanların ortalaması $\overline{\boldsymbol{x}}$ $=3.09 \pm .66$ şeklinde bulunmuştur.

Tablo 4. Voleybolcularn antrenmanlarda ve müsabakalarda kullandiklar psikolojïk performans stratejilerin degerleri ile ilgili t testi sonuclar

\begin{tabular}{|c|c|c|c|}
\hline \multicolumn{4}{|c|}{ Bağımsız Örneklem T testi } \\
\hline Alt Boyutlar & F & $\mathrm{t}$ & Sig. \\
\hline Kendinle Konuşma & .04 & 4.48 & .00 \\
\hline Duygusal Kontrol & 13.62 & 2.14 & .03 \\
\hline Otomatizasyon & 12.66 & 4.13 & .00 \\
\hline Hedef Belirleme & .70 & -1.08 & .28 \\
\hline İmgeleme & 2.96 & -1.33 & .18 \\
\hline Aktivasyon & 9.20 & -3.79 & .00 \\
\hline Negatif Düşünce / Dikkat Kontrolü & 1.30 & 4.69 & .00 \\
\hline Rahatlama Becerisi & .01 & 4.80 & .00 \\
\hline
\end{tabular}

Voleybolcuların antrenmanlarda ve müsabakalarda kullandıkları psikolojik performans stratejileri ile ilgili farkllıklar olup olmadığının incelenmesi sonucu elde edilen verilere göre (Tablo4.), antrenman ve müsabakalarda kullanılan psikolojik performans stratejileri arasında iki alt boyut hariç tümünde anlamlı farklılıklara ulaşılmıştır. Buna göre psikolojik performans stratejileri içerisinden hedef belirleme alt boyutu $(\mathrm{t}(266)=-1.08, \mathrm{p}=.28)$ ve imgeleme alt boyutu $(\mathrm{t}(266)=-1.33$, $\mathrm{p}=.18)$ arasındaki fark istatistiksel olarak anlamlı değildir. 
Feralan, A. Ö., İbiş, S., \& Miçooğulları, B. O. (2020). Voleybolcuların psikolojik performans stratejilerinin belirlenmesi. Journal of Human Sciences, 17(3), 812-821. doi:10.14687/jhs.v17i3.5963

Bununla birlikte kendinle konuşma alt boyutu $(\mathrm{t}(266)=4.48, \mathrm{p}=.00)$ için anlamlı farklilık bulunmuştur. Buna göre, antrenmanda kullanılan kendinle konuşma değerleri $(\overline{\boldsymbol{x}}=3.75)$ müsabakalarda kullanılan kendinle konuşma stratejisi değerinden daha yüksektir $(\overline{\boldsymbol{x}}=3.38)$.

Duygusal kontrol alt boyutunda ki analiz ise $(\mathrm{t}(266)=2.14, \mathrm{p}=.03)$ şeklinde anlamlı farklılık olduğu saptanmıştır. Antrenmanda kullanılan duygusal kontrol değerleri $(\overline{\boldsymbol{x}}=3.31)$ müsabakalarda kullanılan duygusal kontrol stratejisi değerinden $(\overline{\boldsymbol{x}}=3.38)$ daha fazla olarak saptanmıştır. Bir diğer alt boyut olan otomatizasyon stratejisinde ise $(\mathrm{t}(266)=4.13, \mathrm{p}=.00)$ düzeyinde anlamlı farklillk bulunmuştur. Buna göre, antrenmanda kullanılan otomatizasyon alt boyutu değerleri $(\overline{\boldsymbol{x}}=3.52)$ müsabakalarda kullanılan otomatizasyon stratejisi kullanımı değerinden daha yüksektir $(\overline{\boldsymbol{x}}=3.11)$.

Aktivasyon alt boyutunda ki analiz ise $(\mathrm{t}(266)=3.80, \mathrm{p}=.00)$ şeklinde anlamlı farklllik olduğu saptanmıştır. Bu anlamlı farkın sebebi, müsabakalar sürecinde kullanılan aktivasyon değerleri $(\overline{\boldsymbol{x}}=$ 3.60) antrenmanlarda kullanılan aktivasyon stratejisi değerinden $(\overline{\boldsymbol{x}}=3.25)$ daha fazla olmasina bağlıdır.

Antrenmanlarda kullanılan dikkat kontrolü alt boyutu ile müsabakalarda kullanılan negatif düşünce alt boyutları arasındaki analiz ise $(\mathrm{t}(266)=4.68, \mathrm{p}=.00)$ şeklinde anlamlı farklılık göstermiştir. $\mathrm{Bu}$ anlamlı farklığının, antrenmanda kullanılan dikkat kontrolü değerlerinin $(\overline{\boldsymbol{x}}=3.22)$ müsabakalarda kullanılan negatif düşünce stratejisi değerinden $(\overline{\boldsymbol{x}}=2.86)$ daha fazla olması sebebiyle dikkat kontrolü yönünde olduğu saptanmıştır.

Antrenmanlarda ve müsabakalarda kullanılan performans stratejileri arasinda incelenen son alt boyut rahatlama becerisi stratejisi olmuştur. Görülmüştür ki rahatlama becerisi stratejisinde $(\mathrm{t}(266)=4.80, \mathrm{p}=.00)$ şeklinde anlamlı farklılık vardır. Bu anlamlı farklığının, antrenmanda kullanılan rahatlama becerisi değerlerinin $(\overline{\boldsymbol{x}}=3.47)$ müsabakalarda kullanılan rahatlama becerisi stratejisi değerinden $(\overline{\boldsymbol{x}}=3.09)$ daha fazla olması sebebiyle antrenmanlar yönünde olduğu saptanmıştır.

\section{Tartışma}

Yapılan çalışmada voleybolcuların antrenmanlarda ve müsabakalarda kullandıkları psikolojik performans stratejilerinin belirlenmesi ve bu becerilerin antrenman ve müsabaka ortamlarında kullanılma düzeylerinin karşılaştırılması amaçlanmıştır.

İçinde bulunduğumuz çağda sportif anlamda başarı anlayışı, sadece fiziksel özelliklerin üst düzey olması ile değil, aynı zamanda psikolojik süreçler ile ilgili özelliklerin de üst düzey olması gerekliliği olarak beklenmektedir. Bu psikolojik özellikler tüm sportif uygulamalarda ön plana çıkmaktadır. Psikolojik özelliklerin doğru seçilmiş stratejiler ile daha doğru kararlara vesile olacağının tüm branşlarda ki sporcuların için önemli ve değerli bir süreç olacaktır. Seçilen psikolojik performans stratejileri ile ilgili yapılan bilimsel çalışmalar bu bölümde sunulacaktır.

Elit sporcuların psikolojik performans stratejilerini kullanma düzeylerinin elit olmayan sporculara göre farklılık olup olmadığının bulunması amacıyla yapılan bir çalışmada elit sporcuların daha yüksek düzeylerde stratejilerden faydalandıkları bulunmuştur. Cinsiyet farklıllğı özelinde ise kadın sporcuların duygusal kontrol ve rahatlama becerisi stratejilerinde erkek sporculara göre daha düşük düzeyde etkili oldukları saptanmıştır (Katsikas ve ark., 2009). Bu çalışmamızın sonuçları çalışmamız sonuçlarını destekler niteliktedir.

Diğer bir çalışmada Harwood ve arkadaşları, genç elit sporcuların başarı hedef yönelimi profilleri ile kullandıkları psikolojik performans stratejileri arasındaki ilişkileri incelemeyi amaçlamışır. Çalışma içerisinde 4 farklı motivasyon profili 4 farklı grup oluşturarak belirlenmiştir. Bu profiller ile psikolojik performans stratejileri arasındaki sonuçlar ise yüksek ve orta düzey görev yönelimli sporcuların düşük düzeyde görev yönelimli elit genç sporculara göre daha yüksek oranda imgeleme, kendinle konuşma, ve hedef belirleme stratejilerini kullandıklarını saptamışlardır (Harwood ve ark., 2004). Çalışma sonuçları yapılan çalışma ile benzer sonuçlar içermektedir.

Benzer bir çalışmada Tanaka ve Gould (2015) farklı kategorilerdeki 18 -38 yaşları arasındaki 95 tanesi Süper Ligden ve 257 tanesi de üniversite takımlan ve amatör liglerden seçilen toplam 352 rugby sporcusunun kullandıkları psikolojik performans stratejileri arasındaki olası farklılıkları 
Feralan, A. Ö., İbiş, S., \& Miçooğulları, B. O. (2020). Voleybolcuların psikolojik performans stratejilerinin belirlenmesi. Journal of Human Sciences, 17(3), 812-821. doi:10.14687/jhs.v17i3.5963

bulmayı amaçlamışlardır. Çalışma sonuçları incelendiğinde müsabaka alt ölçeğinde; hedef belirleme, imgeleme, duygusal kontrol ve aktivasyon stratejilerinin daha fazla ortalamaya ulaştığını belirlemişlerdir. Antrenman alt ölçeği incelendiğinde ise imgeleme, kendinle konuşma duygusal kontrol ve aktivasyon stratejilerin daha yüksek ortalamaya ulaştı̆ı̆ı saptamışlardır. Elde edilen sonuçlar yapılan çalışmada elde edilen sonuçlar ile benzerlikler taşımaktadır.

Clowes ve Knowles (2013) yaptıkları çalısmada performans öncesi rutinlerinde artistik jimnastik sporcularının kullandıkları psikolojik performans stratejilerinin belirlenmesini amaçlamıştır. Bu amaçla 9 elit bayan artistik jimnastikçi ile çalışmayı gerçekleştirmişlerdir. Çalışma sonuçları detaylı şekilde incelendiğinde imgeleme, kendinle konuşma ve aktivasyon kontrolü stratejilerinin elit bayan artistik jimnastikçiler de daha dominant olduklarını bulmuştur.

Benzer bir çalısmada akrobatik jimnastik branşında elit bir sporcu ile yapılan vaka çalışması içerisinde sporcunun müsabaka öncesi rutinlerini belirlemek amaciyla uyguladiğ1 performans stratejilerinin belirlenmesi hedeflenmiştir. Ek olarak bu sporcunun kendini psikolojik beceriler anlamında geliştirmesi amacıyla PBA kullanılmıştır. Çalışma sonucunda sporcunun PBA öncesinde antrenman alt ölçeğinde en fazla hedef belirleme, dikkat kontrolü imgeleme ve duygusal kontrol stratejilerini kullandığ1; müsabaka alt ölçeğinde ise negatif düşünce ve duygusal kontrol stratejilerini diğerlerine oranla daha fazla kullandığı saptanmıştır. Uygulanan PBA sonrasında ise antrenman alt ölçeğinde en fazla gelişim yüzdesini rahatlama stratejisinde yakaladığı fakat hala hedef belirleme, dikkat kontrolü imgeleme ve duygusal kontrol stratejilerini en yüksek oranlarda kullandığ1; müsabaka alt ölçeğinde de en fazla gelişim yüzdesine rahatlama stratejisinde ulaştığı ve en yüksek ortalamalara da imgeleme ve hedef belirleme stratejilerinde ulaştığı bildirilmiştir (Faggiani ve ark., 2011).

Bir diğer çalışmada engelli sporcuların sahip oldukların sahip oldukları psikolojik performans stratejilerinin belirlenmesi amaçlanmıştır. Toplamda 70 engelli sporcunun katıldı̆g çalışmada, otomatizasyon ve aktivasyon stratejileri dışında kalan tüm stratejilerin istenilen değerler ve daha yüksek değerlere ulaştıkları saptanmıştır (Bastos ve ark., 2012).

Dachen (2012) yılında yaptığı çalışmada 36 erkek ve 32 kadın toplamda 68 üniversite sporcu öğrencinin psikolojik performans stratejilerinde ki olası kullanma farklıllklarını incelemeyi amaçlamıştır. Çalışmanın sonuçları detaylı incelendiğinde, hem cinsiyet değişkenine göre hem de takım - bireysel sporlar karşılaştırmasına göre anlamlı farklılıklara ulaşılmıştır. Hem antrenman hem de müsabaka stratejileri incelendiğinde kadın sporcuların hedef belirleme, kendinle konuşma, imgeleme ve dikkat kontrolü/negatif düşünce stratejilerinde erkek sporculara göre daha dominant olduklarını saptamıştır. Takım sporcularının rahatlama becerisi ve aktivasyon stratejilerinde bireysel sporculara göre daha yüksek düzeyde olduğunu belirlemiştir. Bireysel sporcuların ise duygusal kontrol stratejilerinde takım sporcularından daha etkili olduğunu ifade etmiştir.

Duygusal zeka ve psikolojik performans stratejileri kullanım düzeyleri arasındaki ilişkinin bulunmasının amaçladığı çalışmada, futbol, hokey ve rugby branşlarından 18'er kişi olacak şekilde toplam 54 sporcu kullanılmışır. Çalışmanın sonuçları incelendiğinde ise özellikle kendinle konuşma, imgeleme ve aktivasyon stratejilerinin duygusal zekası yüksek olan sporcularda ki dominant stratejiler oldukları ortaya konmuştur (Lane ve ark., 2009).

\section{Sonuç}

Yapılan çalışma lisanslı ve müsabık şekilde olan 14-25 yaş arası Voleybolculara uygulanmıştır. Elde edilen sonuçlar incelendiğinde; Antrenman alt ölçeğinde kullanılan stratejiler arasında en yüksek ortalama kendinle konuşma becerisi; en az kullanılan ise dikkat kontrolü saptanmıştır. Müsabaka alt ölçeğinde ise en fazla kullanılan strateji olarak da aktivasyon becerisi; en düşük düzeyde kullanılan beceri stratejisi de rahatlama olarak bulunmuştur. Kullanılan becerilerin karşılaştırılması sonucunda hedef belirleme ve imgeleme becerileri dışındaki tüm becerilerde anlamlı farkl1lik bulunmuştur.

Çalışmada temel anlamda psikolojik performans stratejilerinin kullanım düzeylerinin belirlenmesi amaçlanmıştır. Gelecekte yapılacak çalışmalarda cinsiyet değişkeni, kullanım oranlarına 
Feralan, A. Ö., İbiș, S., \& Miçooğulları, B. O. (2020). Voleybolcuların psikolojik performans stratejilerinin belirlenmesi. Journal of Human Sciences, 17(3), 812-821. doi:10.14687/jhs.v17i3.5963

göre ayrıştırılmış gruplar (yüksek - orta - düşük), farklı kategorilerde ki sporcuların karşılaştrılması gibi zenginlik artturıcı perspektiflerde kullanılabilir. Ek olarak yaş değişkeni boyutunda daha geniş bir yelpaze ile yapılacak çalışmalar önerilebilir. Ayrıca ülkemizde dünya çapında başarılara imza atmış olan elit voleybol takımlarına ulaşılma olasıllı̆ına sahip olunur ise ülkemizde ki elit voleybolcuların kullandıkları stratejilerin belirlenmesi, onlar gibi olmaya çalısan yeni nesillerin hangi konularda daha fazla eğitilmeleri gerektiği ile ilgili çok değerli sonuçlar verebilir. Son olarak tüm dünya üzerinde yaygın kullanılmaya başlayan psikolojik beceri antrenmanları ile bütünleşik bir şekilde psikolojik performans stratejilerinin geliştirilmesi spor psikolojisi alanına çok değerli bilgiler katabilir.

\section{Kaynaklar}

Aşçı, H., Doğu, G., Yaman, H., Mirzeoğlu, N., Çelebi, M., Kirazcı, S., Mirzeoğlu, D., Özbey, S., Bağırgan, T. (2011). (Editör: Nevzat Mirzeoğlu). Spor Bilimlerine Giriş: 129-169, (3.Baskı), Spor Yayınevi, Ankara.

Bastos, T. L., Correderia R., Probst M., Fonseca A. M., (2012). Preliminary Analysis of The Psychometric Properties of the Portuguese Version of The Test of Performance Strategies (TOPSp) In Athletes With Disabilities, European Journal of Adapted Physical Activity, 5 (2): 7 22.

Brewer, B.W. (2009). Injury prevention and rehabilitation. In B. W. Brewer (Ed.), Sport Psychology (pp. 83-96). Chichester, UK: Wiley-Blackwell.

Burton, D., \& Raedeke, T. (2008). Sport psychology for coaches. Champaign, IL: Human Kinetics.

Clowes, H., \& Knowles, Z. (2013). Exploring the Effectiveness of pre-performance routines in elite artistic gymnasts: A mixed method investigation. Science of Gymnastics Journal 5:2, 27-40.

Dachen, J. (2012). Test of performance strategies among college going athletes: difference across type of sports and gender. International journal of behaviour social and movement sciences, 1, 22777547.

Faggiani, F., McRobert, A. P., ve Knowles, Z. (2012). Developing pre-performance routines for acrobatic gymnastics: a case study with a youth tumbling gymnast. Journal of Science Gymnastic, 4, 39-52.

Hanton, S., Wadey, R., \& Mellalieu, S.D. (2008). Advanced psychological strategies and anxiety responses in sport, The Sport Psychologist, 22, 472-490.

Harwood, C., Cumming, J., \& Fletcher, D. (2004). Motivational profiles and psychological skills use within elite youth sport. Journal of Applied Sport Psychology, 16, 318-332.

Holland, J. G., Woodcock, C., Cumming, J., \& Duda, J. L. (2010). Mental qualities and employed mental techniques of young elite team sport athletes. Journal of Clinical Sport Psychology, 4, 19-38.

Kalmar Z., Nagykaldi C., Balazsi R., Munkacsi I., Soos I., Toth L. ve Hamar P., (2014). Comparative Analysis of the Results of Performance Strategies Tests Between British and Hungarian Female Gymnasts, Cognition, Brain, Behavior. An Interdisciplinary Journal, (4); 335-347.

Karasar, N. (2015). Bilimsel araştırma yöntemi. Ankara: Nobel Yayınları.

Katsikas, C., Argeitaki, P., \& Smirniotou, A. (2009). Performance strategies of Greek track and field athletes: Gender and level differences. Journal Biology of Exercise, 5(1). doi:10.4127/jbe.2009.0023

Karageorghis, C. I., \& Terry, P. C. (2009). The psychological, psychophysical and ergogenic effects of music in sport: A review and synthesis. In A. J. Bateman \& J. R. Bale (Eds.), Sporting sounds: Relationships between sport and music (pp. 13-36). London: Routledge.

Lane AM, Thelwell RC, Lowther JP, Devonport TJ., (2009). Relationships between emotional intelligence and psychological skills among athletes. Social Behaviour and Personality: An International Journal, 37: 195-202. 
Feralan, A. Ö., İbiș, S., \& Miçooğulları, B. O. (2020). Voleybolcuların psikolojik performans stratejilerinin belirlenmesi. Journal of Human Sciences, 17(3), 812-821. doi:10.14687/jhs.v17i3.5963

Mahoney, M.J., Gabriel, T.J., \& Perkins, T.S. (1987). Psychological skills and exceptional athletic performance. Sport Psychologist, 1, 181-199.

Mckay, E.G., (2001). Strategic Planning: A Ten Step-Guide, World Bank, USA.

Moran, A.P. (2004). Sport and Exercise Psychology, Routledge, New York.

Miçooğulları, B.O., (2017). Reliability and Validity of the Turkish Language Version of the Test of Performance Strategies. Montenegrin Journal of Sports Science \& Medicine, 1:73-79.

Tanaka S, Gould D., (2015). Psychological skills usage among Japanese rugby players. International Journal of Sport and Exercise Psychology, 13(4):309-319.

Thomas P, Murphy S, Hardy L. (1999). Test of performance strategies: Development and preliminary validation of a comprehensive measure of athletes' psychological skills. Journal of Sport Sciences, 17, 697-711.

\section{Extended English Summary}

Athletes can show expected performance, apply selected game strategies more effective than others and they can find more creative solutions for faced problems, if they choose right psychological performance strategies even under pressure situations. Moreover, they are able to concentrate effectively, force their capacity and they can learn new techniques quickly than others. Athletes' psychological advantages evaluate in sport psychology discipline (Mckay, 2001).

While psychology science is defined as the science that tries to explain behaviors and mental processes; Sports Psychology is described as a science that tries to explain mental processes in a sportive context. (Brewer, 2009). Sports psychology encompasses not only athlete behavior, but also people who makes physical activities for recreational exercise, leisure time and fitness. (Moran, 2004). At the same time, sports psychology is a discipline. It includes a theoretical infrastructure as well as an infrastructure that can be examined practically. (Moran, 2004). Sports psychology is universally applicable to many principles related to successful performance in sports. (Aşçı et al., 2011). While sports psychology enriches the lives of athletes; strengthens athletes by increasing their sports performance through practices (for instance psychological skill training). (Karageorghis \& Terry, 2009).

Many scientific studies have determined the contribution of psychological skill training to athletes' performance and many social-psychological parameters in their daily lives. One of the most valid ways to determine whether the psychological skill training applied to athletes is effective and efficient is to determine the psychological performance strategies used by the athlete against the psychological processes encountered in training and competitions (Burton \& Raedeke, 2008).

Our responses to problematic situations encountered in sports environments depend heavily on interpretive and experiential factors, and these responses are individual and specific. Each athlete differs according to their preferences to approach the developing events. This obvious point of view shows that certain mental strategies are more suitable for each athlete than for others. Different athletes may do better with certain strategies, while others may not. These processes can be explained as different psychological strategies used by athletes. (Thomas et al., 1999). Scientific studies those aimed to determine psychological performance strategies of athletes began with the Psychological Performance scale developed by Loehr in 1986. Later, Mahoney et al. (1987) have developed the Scale of Psychological Skills in Sports which has been used many times until today. The last scale organized to measure and determine psychological performance strategies is the scale of psychological performance strategies organized by Thomas et al. In order to determine the psychological processes and parameters underlying "successful athlete performances".

When the scientific results related to this study's aim was examined detailed. It is found that the strategies and usage levels of athletes under the heading of psychological performance strategies are important for successful sports performance, and many coaches state that athletes should pay attention to these facts while planning their psychological performance. (Thomas et al., 1999; Hanton et al., 2008; Holland et al., 2010; Clowes \& Knowles, 2013; Kalmar et al., 2014; Tanaka \& Gould, 2015; Miçooğulları, 2017). 
In this study, it was aimed to determine the psychological performance strategies of the volleyball players.

The sample of the study is consisted of athletes aged 15-24 who are dealing with the Volleyball branch in Nevşehir province. 134 athletes aged between 15-24 years voluntarily participated in the study. The sample of the study was selected from the athletes who train at least 3 days a week in terms of their branches. The athletes were informed about the purpose of the study, their wish and motivation levels were increased and their participation at the maximum level was ensured.

To collect data, the Test of Performance Strategies (TOPS), was used in order to evaluate the performance strategies of athletes. TOPS inventory is consisted of eight subscales with total 60 items (30 items for competition and 30 items for practice scale): self-talk, emotional control, automaticity, goal-setting, imagery, activation, relaxation and negative thinking (for practice scale it is replaced with attention control). Answers are given on a 5-point Likert type scale ranging from 1 (never) to 5 (always). The validity and reliability of the competition scale of TOPS in Turkish athletic population has already been examined (Micoogullari, 2017). The results supported the initial factorial structure and provided adequate evidence for the internal consistency.

To examine the performance strategies of volleyball players and also comparison of usage levels of strategies in training and competitions Independent Sample t test was employed to find out the intra-group differences.

Practice scale's highly used strategy was self-talk and the lowest usage percentage was attention control. Meanwhile, competition scale results indicated that the highest used strategy was activation and lowest used strategy was relaxation. While comparison of differences between practice and competition scales strategies it is found that except of goal setting and imagery all other strategies showed significant differences.

Finally, psychological performance strategies' averages of volleyball players were ensured and it is exhibited that to which strategies should be thought and focused. 